\title{
LA MUJER EN LA GUARDIA CIVIL: \\ Una perspectiva sociológica
}

\section{Gonzalo Jar Couselo}

RESUMEN. Se trata de analizar las variables sociológicas que condicionan los procesos de selección, formación y asignación de puestos de trabajo a las mujeres en la Guardia Civil, a partir de su ingreso en la institución (1988), con especial referencia a los fenómenos de autorreclutamiento y endogamia y, en definitiva, a determinar la tendencia mayoritaria dentro del ya clásico dilema entre el modelo institucional y el ocupacional.

Un análisis de la presencia femenina en la Guardia Civil tiene por fuerza que comenzar, al menos, con una referencia a una experiencia no demasiado conocida en ambientes ajenos a los de la propia institución, pero que, sin embargo, no dejaba de ser un fenómeno interesante en la medida que podría servir de indicador de las posibilidades de integración de la mujer en una organización típicamente militar como la de la Guardia Civil y, por consiguiente, de pauta para la próxima llegada de agentes femeninos a la misma.

De manera un tanto paradójica, al tratarse de un Cuerpo militar de tanta raigambre en la historia de España, lo que iba a ser una innovación para el mundo castrense de nuestro país - la incorporación de la mujer a las FAS - no lo fue tanto para la Guardia Civil, ya que desde 1948 venían prestando servicio en la misma agentes femeninos, bien es verdad que a través de una figura un tanto peculiar como era la de la matrona. Dicha presencia vino condicionada por la fusión, tras la guerra civil de 1936, de

\section{Reis}


los Cuerpos de la Guardia Civil y Carabineros, al ser necesaria la presencia femenina en los recintos aduaneros para efectuar funciones de control y registro sobre personas del mismo sexo, razón por la que era muy frecuente contemplar en puertos y aeropuertos mujeres vestidas con el típico uniforme verde, las que, sin embargo, no gozaban de la misma consideración que el resto de miembros de dicho Cuerpo, al no tener el carácter de funcionaria y acceder al mismo por criterios totalmente distintos a los habituales en la Administración; en general, eran reclutadas entre viudas y huérfanas de guardias civiles, lo que implicaba que tuvieran que regirse por una reglamentación ajena a la del resto del personal, y en ningún caso pudiesen portar armas.

Cuando, a mediados de la década de los años ochenta, se comienza a debatir en torno a la necesidad de la incorporación plena de la mujer a las FAS, el papel de la matrona entra necesariamente en crisis, motivo por el que en 1986 se declara a extinguir ese Cuerpo especial, lo que no impide que, de forma un tanto extraña, se proceda a convocar al año siguiente la que iba a ser primera y única promoción de matronas de la Guardia Civil, a las que, aun reconociéndosele su peculiaridad, no impide que se les imparta en la Academia de Sabadell una instrucción típicamente militar. La entrada en servicio de éstas coincidirá con el anuncio de la primera promoción de guardias civiles abierta a las mujeres, lo que suponía de hecho la desaparición de aquéllas, tal y como se encargaron de recoger dos disposiciones del Ministerio del Interior, de finales de 1990, en las que se regulaba el régimen de ese personal y el de provisión de puestos de trabajo, en ambos casos similares a los de la Administración civil del Estado.

La prueba de la inviabilidad de ese modelo tradicional era que, en ausencia de matronas, se establecía que el servicio de reconocimiento de mujeres sería atendido por guardias civiles femeninos, en su doble condición de policía judicial y de resguardo fiscal. Por todo ello, las 140 matronas existentes en 1991 comenzaron a denunciar públicamente su situación laboral y lo que consideraban discriminación respecto al resto de funcionarios de Interior, ya que, según ellas, seguían bajo disciplina militar y uniformadas - sin emblemas ni pistola- y sometidas a presiones para que solicitasen la baja; asimismo, recuerdan que percibían un salario menor al de una guardia civil, al haber sido incluidas en el grupo $\mathrm{E}$ de funcionarios - estaban pendientes de reclasificación, ya que estos funcionarios iban a ser sustituidos progresivamente por contratados laborales-, razones por las que reclaman su incorporación a la Guardia Civil como miembros ordinarios o a otro destino de la Administración sin pérdida de derechos económicos. En todo caso, el conflicto planteado no era más que la consecuencia de una decisión un tanto incomprensible como la de haber convocado una oposición de este tipo tan sólo un año antes de que se hiciese efectivo el ingreso de la mujer en la Guardia Civil, toda vez que estas matronas, por el propio sistema de acceso, eran muy distintas a las que 
habían venido funcionando de manera un tanto paternalista desde 1950, fecha en la que se dictó su reglamentación propia. Los beneficios de tal experiencia iban a servir para hacer frente a la nueva problemática que presentaría la incorporación efectiva de la mujer a la Guardia Civil, ahora sí con tricornio y pistola.

El artículo 41 de la Ley del Servicio Militar de 1986 establecía que el servicio de la mujer sería «regulado por la ley que determine su participación en la defensa nacional», regulación que algunos sectores consideraban totalmente insuficiente - hasta entonces, sólo el Cuerpo de Damas de Sanidad Militar y el femenino de la Marina (auxiliares y técnicos de la Escuela de Guerra Naval) prestaban servicio en las FAS- y que tuvieron en la figura de Ana Moreno la representación de tales carencias. Esta joven comenzaría en 1987 una larga batalla jurídica para poder opositar a la AGA, pretensión repetidamente rechazada en base a la falta de normativa legal y, en principio, a una interpretación restrictiva del requisito de «ser español», que le llevaría hasta el Tribunal Constitucional, el que dictó una sentencia en 1991 favorable a las tesis de la aspirante, sin que le sirviese para ingresar en las FAS debido a haber superado la edad máxima establecida.

No obstante, este trabajo pretende centrar su interés de forma casi monográfica en el Cuerpo de la Guardia Civil —Cuerpo de naturaleza militar pero con funciones policiales-, ya que, recién llegado el primer civil que iba a dirigirlo — Luis Roldán, en noviembre de 1986_, da a conocer su intención de incorporar en breve plazo a la mujer a dicha institución, para lo cual será necesario contar previamente con el marco legal que lo permita. Es por ello que hasta la promulgación del importante RD-Ley 1/1988 (de 22-II), que regulaba la incorporación de la mujer a las FAS, no fue posible poner en marcha dicho proceso, al recoger su artículo $3 .^{\circ}$ que «la mujer tendrá acceso a las pruebas de selección para el ingreso como Guardias civiles de segunda»; por cierto, conviene llamar la atención sobre un hecho que parece determinante, cual es el de que para el resto de Cuerpos - todos de carácter técnico o auxiliar - el nivel de empleo para la mujer era de suboficial y oficial, lo que iba a permitir un conocimiento bastante exacto de la respuesta que darían unas clases de tropa femeninas en un Cuerpo militar, como era el caso de la Guardia Civil.

Aunque sea de forma esquemática, conviene subrayar que el citado RD era una consecuencia de las leyes orgánicas de Criterios Básicos de la Defensa Nacional y del Plan para la igualdad de oportunidades de la mujer, lo que había propiciado un acuerdo del Consejo de Ministros de septiembre de 1987. Se establecía en el preámbulo de la norma que no podrían existir en los procesos de selección más diferencias que las derivadas de las «distintas condiciones físicas», que la mujer podrá alcanzar «todos los empleos militares» - sin que exista distinción terminológica alguna con el varón- y que los destinos a ocupar serán los mismos que los de los hombres, salvo los que se deriven de las «condiciones fisiológicas». Cuando fue convalidado 
en las Cortes (10-III), los grupos de la oposición se quejaban de que solamente permitiese el acceso a Cuerpos técnicos - R. Tamames planteó el interrogante de si la mujer tendría que realizar el servicio militar obligatorio, cuestión clave desde el punto de vista de la igualdad-, anunciando el Gobierno que pronto se debatiría la ley de la función militar.

En marzo de ese mismo año se anuncia la primera convocatoria libre para ingreso en dicho Cuerpo, en la que las pruebas psicotécnicas y culturales son las mismas para hombres y mujeres y las médicas y físicas tienen un carácter específico para unos y otras $\mathrm{y}$, por tanto, puntuaciones distintas. Si bien la previsión inicial era restringir a 150 el cupo de mujeres, con el pretexto de poder ir formando unas escalas de suboficial y oficial femeninas, la realidad legal es que no existió tal limitación, aun cuando los resultados finales de la selección hiciesen sospechar sobre la existencia de algún mecanismo corrector.

La llegada de las primeras alumnas levantó la lógica expectación, recogida oportunamente por los distintos medios de comunicación, reflejándose en éstos determinadas anécdotas, como la Ilegada de un camión a la Academia cargado de compresas o la adjudicación de camisetas de gimnasia iguales a las de los hombres, las que hubieron de ser cambiadas de inmediato por dejar al descubierto gran parte del torso de las mujeres. Aunque en un principio se pensó aislar a éstas de los hombres, finalmente se integran unos y otras en la práctica totalidad de actividades, si bien desde la dirección del centro se dictaron normas para ejercer un control estricto sobre las posibles relaciones intersexuales, lo que no iba a ser impedimento, como habrá ocasión de comprobar, para que se iniciasen vínculos tan estrechos entre alumnos que desembocarían en el matrimonio.

Las opiniones de las que eran ya pioneras en una experiencia de este tipo no se caracterizaban por su uniformidad y, así, mientras para Virginia «es un reto el que una mujer se meta en una vida tan masculina», Isabel consideraba que «no se puede bablar realmente de integración, pues el cuerpo militar no está todavía mentalizado para que una mujer pueda dar órdenes a un bombre mayor que ella», en tanto Carmen, desde una postura mucho menos clara y tras reconocer que «una mujer no es igual que un hombre», declaraba que «yo no me veo como el clásico guardia civil» y esperaba que, dentro de las muchas salidas que tendría esta profesión, «igual me mandan a una oficina». A pesar de algunas dificultades iniciales, la mayoría logró integrarse en la vida académica y, durante los actos de la patrona de ese año, desfilaba por vez primera una sección compuesta en su integridad por mujeres.

Por esas fechas, el que fuese miembro de la UMD, S. Perinat, en un artículo en Diario 16 (27-X-88) en el que consideraba innecesaria la incorporación de la mujer a las FAS, hacía una serie de matizaciones respecto al caso concreto de la Guardia Civil, al tratarse de algo «más definido»-tiene unas misiones concretas y una necesidad prioritaria de agentes femeninos-, si bien denuncia que «lo artificioso y desaforado es el montaje propa- 
gandístico». Advierte que su presencia causará sorpresas y tendrán que luchar por «imponer su profesionalidad», siendo previsible su paso «con celeridad» a cargos burocráticos y administrativos, mucho más cómodos que «batirse el cobre» por calles, caminos y carreteras, ya que «la berencia genética no perdona». Previene sobre los posibles «favoritismos», inusuales en otros casos según él, aunque sólo sea porque al jefe le guste tener en su antedespacho a una mujer que no a «un civil con bigote», y que, no es de extrañar, muchas de ellas acaben casándose con el coronel. Parece evidente que, para dicho ex militar, la presencia femenina en las instituciones castrenses no pasaba de ser una cuestión trivial que iba a provocar más complicaciones que ventajas a las mismas.

Tras la II Guerra Mundial, a la disminución en el número de hombres disponibles para servir en el ejército norteamericano se une una mayor participación de la mujer en el mercado laboral —redefinición de las tareas femeninas, debido a fuertes presiones para conseguir una legislación que tenga en cuenta el principio de igualdad de oportunidades-, lo que lleva al abandono del servicio militar obligatorio y a la apertura del acceso de las mujeres al mundo militar. El nivel de aceptación hizo que el número no dejase de crecer y, en ese sentido, Shields señala cómo se ha pasado del 2 por 100 en 1970 al 10 por 100 en la actualidad, siempre teniendo en cuenta que, como apunta dicha autora, ese porcentaje es una «fracción mínima del mercado laboral», algo bastante comprensible si se hace caso de Fernández Vargas, para quien las guerras han sido generalmente un asunto de hombres en las que las mujeres participaban pero de una forma «vicaria o subsidiaria». Aun cuando las diferencias no desaparecen por el simple hecho de regularlas legalmente, muchos responsables políticos se han dado cuenta de que se obtendrían mejores resultados reclutando mujeres con las cualidades necesarias que hombres con rechazo a implicarse de lleno en este tipo de cuestiones.

Cuando R. Kanter estudia los procesos de «polarización» derivados de la presencia femenina en las FAS, lo que está es tratando de determinar el nivel o porcentaje a partir del cual es posible la integración sin que la operatividad de las unidades disminuya - en ese sentido, considera que cifras inferiores al 17-20 por 100 constituyen una «coartada social» en la que las mujeres, como "minoría simbólica», se ven abocadas a adoptar estereotipos masculinos para mantenerse en el cargo--; parece evidente que cuanto menor es el número de mujeres, más difícil resulta esa integración, pues los medios de comunicación generan un efecto publicitario negativo al prestar demasiada atención al comportamiento de las mismas. Hay que decir que, en estos momentos y tal como se expone a continuación, ningún país alcanza ese nivel mínimo de participación femenina: 


\begin{tabular}{|c|c|}
\hline & $\%$ \\
\hline 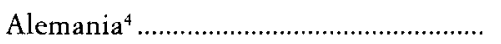 & 0,04 \\
\hline Bélgica $^{2}$ & 3,90 \\
\hline Canadá $\hat{1}^{1} \ldots .$. & $8,4-9,20$ \\
\hline 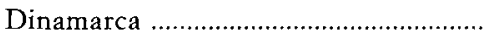 & $2,3-3,00$ \\
\hline EE.UU. ${ }^{1}$ & $9,5-10,2$ \\
\hline 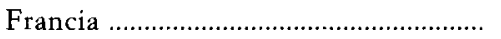 & $2,6-3,70$ \\
\hline Gran Bretaña ${ }^{1}$ & $3-5,00$ \\
\hline 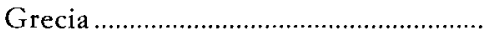 & $0,5-1,00$ \\
\hline Holand $\mathbf{a}^{2}$.. & $0,9-1,50$ \\
\hline Noruega $^{2}$ & $1,1-1,40$ \\
\hline 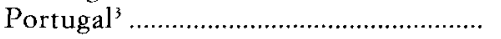 & $0,01-0,03$ \\
\hline
\end{tabular}

${ }^{1}$ Ejércitos profesionales.

${ }^{2}$ Incluye especialidades de combate.

3 Sólo cuenta con diez oficiales.

${ }^{4}$ En tasa de oficiales, el 0,3 por 100.

Fuente: J. Calderón y J. Alemany. «La Mujer en las Fuerzas Armadas en España», Edit. Ministerio de Defensa, Madrid, 1991.

Después de estas reflexiones iniciales, será conveniente entrar en el análisis de los datos concretos disponibles —bastante escasos, por cierto, al no haberse llevado a cabo aún el necesario estudio multidisciplinar de la cuestión-e intentar dilucidar el presunto dilema relativo a la adopción por parte del contingente femenino de la Guardia Civil de las pautas que configuran un modelo institucional $\mathbf{u}$ ocupacional a la hora de ingresar en el Cuerpo y plantearse su futuro profesional.

Es éste el momento de resaltar el hecho de que, hasta ahora, no se haya realizado aún una investigación rigurosa en torno a las consecuencias que el ingreso de la mujer ha tenido para la Guardia Civil, siendo el único estudio digno de consideración el llevado a cabo por el comandante A. Parrilla - profesor en la Academia de Guardias de Ubeda-, si bien su orientación es básicamente psicológica, lo que no ha impedido que puedan ser utilizados los datos por él obtenidos como una de las fuentes principales de este trabajo. El resto ha sido gracias al esfuerzo de varios departamento aislados, cuya conjunción ha permitido obtener las conclusiones que a continuación se exponen; para ello se analizarán las promociones 94, 95, 96 y 97 —esta última recién salida de la Academia-, que se corresponden con los años 1988 y siguientes, considerando en primer lugar las variables relativas a reclutamiento que pueden condicionar tendencias institucionales u ocupacionales de las aspirantes (cuadro 1).

Respecto a la Guardia Civil, se observa un elevado porcentaje de aspirantes femeninas en la primera convocatoria (26,88 por 100) -existía un gran número de mujeres que esperaban tal oferta laboral-, si bien en los años sucesivos irá descendiendo hasta situarse alrededor del 14 por 100 , 


\section{CUADRO 1}

\section{Indices de reclutamiento femenino}

\begin{tabular}{lcccccc}
\hline Promoción & Instancias & Hombres & $\begin{array}{c}\text { Mujeres } \\
(\%)\end{array}$ & Alumnos & $\begin{array}{c}\text { Mujeres } \\
(\%)\end{array}$ & $\begin{array}{c}\text { Hijas Cuerpo } \\
(\%)\end{array}$ \\
\hline $94(1988)$ & 10.480 & 7.663 & $2.817(26,88)$ & 2.495 & $197(7,89)$ & $91(46,19)$ \\
$95(1989)$ & 11.115 & 8.990 & $2.125(19,12)$ & 3.410 & $180(5,28)$ & $100(55,56)$ \\
$96(1990)$ & 13.439 & 11.551 & $1.888(14,05)$ & 4.151 & $281(6,75)$ & $98(34,86)$ \\
$97(1991)$ & 12.326 & 10.512 & $1.814(14,76)$ & 3.898 & $287(7,29)$ & $108(37,63)$ \\
\hline
\end{tabular}

Fuente: Elaboración propia sobre datos de la DGGC y A. Parrilla.

cifra, por cierto, nada desdeñable si se tienen en cuenta las peculiaridades corporativas de la institución, pero en cualquier caso enmarcada en los parámetros habituales de otras experiencias similares en países del mismo entorno sociopolítico, en concreto en el caso de la Gendarmería francesa -al igual que el resto de las FAS, no pueden superar el nivel del 7 por 100-, pues los Carabinieri italianos, como integrantes de las FAS, no han incorporado definitivamente a la mujer todavía, y la Gendarmería belga desmilitarizada hace muy poco tiempo, nunca superó el 4 por 100 .

Si la tesis ocupacional depende fundamentalmente de las variables salario y tasa de desempleo, se puede convenir con los resultados de estudios realizados en otros países en los que, preguntados por las razones de su ingreso en las FAS, colocan dichas circunstancias en los últimos lugares de preferencia, pues aun cuando la necesidad de encontrar empleo, mantenerse a sí mismas y entrar en el mundo adulto han de ser consideradas a la hora de tomar esa decisión, el recibir un salario generalmente superior a los similares del sector civil y conseguir una definitiva seguridad en el empleo tampoco deben de ser minusvaloradas en ese análisis; por todo ello parece que las cualidades institucionales de los Cuerpos armados -disciplina, estructura organizativa, valores, etc.- les brindan una posibilidad de mejora y satisfacción personal que no encuentran en la vida civil, en especial lo que Shields denomina "desafios nuevos y estimulantes», de donde se deduce que el rechazo de la mujer a los valores ocupacionales de las FAS se complementa con un reforzamiento de las orientaciones institucionales de las mismas.

En el caso concreto de la Guardia Civil, esa tendencia institucional se ve reforzada si se observan los altos índices de autorreclutamiento que figuran en el mismo cuadro -bajo la denominación de lo que a nivel interno se conoce como bijos del Cuerpo, es decir, aquellas mujeres cuyo padre pertenece a la institución-, mucho más elevadas en las dos primeras promociones (el 55,56 por 100 de las mujeres ingresadas en 1989) y con tendencia a estabilizarse en las siguientes en torno al 35-40 por 100, cifras en todo caso muy significativas. 
En cuanto a los procesos de selección, rodeados los primeros años de cierta polémica, permiten deducir algunas conclusiones de interés; así, la más evidente es el rigor de las pruebas, que afecta de forma desigual a hombres y mujeres, al menos en las promociones 94 y 95 , ya que los porcentajes de mujeres aprobadas son tan sólo del 7,89 y 5,28 por 100 del total de inscritos - para unas tasas de aspirantes femeninas del 26,88 y 19,12 por 100 , respectivamente-, mientras que los relativos a hombres multiplican por tres y cuatro los índices de opositores masculinos, tendencia que se ha visto relativamente modificada en los dos años siguientes, al acercarse al 50 por 100 de inscritas $-6,75$ y 7,29 frente a 14,05 y 14,76 por 100 , para las promociones 96 y $97-$, magnitudes que sorprenden más cuando se analizan los niveles culturales de unos y otras, como habrá ocasión de comprobar. Aun cuando podrían alegarse otras razones, existe unanimidad a la hora de atribuir la causa de ese desajuste a la regulación de las pruebas físicas que se hace en la oposición, ya que, aun siendo distintas de las de los hombres, tienen un efecto discriminador que perjudica claramente a las mujeres; de esa manera, y aparte de que en la primera promoción hubiesen sido eliminadas un 26 por 100 de mujeres por no alcanzar la talla fijada, la dureza de las pruebas físicas queda de manifiesto cuando se contemplan los porcentajes de eliminados en las mismas para las promociones 96 y 97 , por cierto las menos rigurosas de las cuatro:

\begin{tabular}{|c|c|c|}
\hline & Hombres & Mujeres \\
\hline 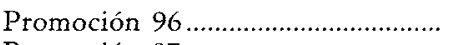 & 4,96 & 58,75 \\
\hline 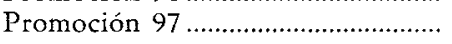 & 5,17 & 58,25 \\
\hline
\end{tabular}

De esa manera, parece claro que las mujeres que finalmente acceden al Cuerpo son las más aptas físicamente, quedando fuera de tal opción cerca del 60 por 100 de aspirantes femeninas, discriminación que se agrava de cara a la puntuación final, ya que la nota obtenida en estas pruebas incide en la misma según baremos preestablecidos. Hay que señalar que cada vez es menos importante en un elevado número de puestos militares la fuerza física y que, cuando la mujer comprueba que puede superar esas pruebas como los hombres, consigue afianzar la confianza en sí misma y le es posible mejorar su nivel de integración en la vida castrense, donde en muchos casos el prestigio se basaba en este tipo de aptitudes. No debe olvidarse que la mujer, como cualquier representante de una minoría, debe convencer a la mayoría de sus habilidades en determinados campos de la actividad laboral.

A pesar de esa primera conclusión, el análisis de los niveles de estudio de las mujeres que logran ingresar en la Guardia Civil parece poner en entredicho la misma (cuadro 2), al menos en lo que se refiere a la primera 


\section{CUADRO 2}

Nivel de estudios de alumnos de la Academia

\begin{tabular}{|c|c|c|c|c|c|c|c|c|c|}
\hline & \multicolumn{3}{|c|}{ Promoción 94} & \multicolumn{3}{|c|}{ Promoción 95} & \multicolumn{3}{|c|}{ Promoción 96} \\
\hline & Hombres & Mujeres & Total & Hombres & Mujeres & Total & Hombres & Mujeres & Total \\
\hline EGB & 35,32 & 12,00 & 33,44 & 55,21 & 40,78 & 53,72 & 36,68 & 32,50 & 36,32 \\
\hline FP1 & 17,35 & 7,50 & 16,56 & 14,50 & 4,47 & 13,78 & 13,89 & 13,21 & 13,82 \\
\hline 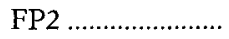 & 3,38 & 8,00 & 3,76 & 4,43 & 5,03 & 4,39 & 6,73 & 3,57 & 6,50 \\
\hline BUP …...................... & 34,69 & 30,00 & 34,33 & 12,14 & 12,28 & 12,15 & 32,20 & 27,49 & 31,92 \\
\hline COU .................... & 3,99 & 18,00 & 5,13 & 7,60 & 20,11 & 8,26 & 7,63 & 11,43 & 7,87 \\
\hline CAU ...................... & 4,56 & 10,00 & 5,00 & 4,17 & 10,61 & 4,52 & 1,73 & 7,86 & 2,14 \\
\hline Universitarios .... & 0,75 & 14,50 & 1,78 & 1,94 & 6,70 & 2,20 & 1,05 & 4,29 & 1,27 \\
\hline
\end{tabular}

Fuente: Elaboración propia sobre datos de A. Parrilla.

promoción, en la que el nivel de EGB es tres veces superior para hombres, mientras en los de COU y superiores la mujer aporta unos porcentajes mucho más elevados que los que corresponden a aquéllos, tendencia que, aun manteniéndose en líneas generales en las promociones siguientes, parece comenzar a quebrarse en beneficio de unas cifras algo más homogéneas para unos y otras, si bien las diferencias siguen siendo todavía significativas. Es explicable que la primera de esas promociones aportase tales niveles, en base a ese mercado potencial del que se ha hablado anteriormente, regularizándose el mismo en sucesivas convocatorias, con lo que parece que en un futuro no muy lejano la equiparación de titulaciones será una realidad. En cuanto a lo que en EE.UU. se considera espectacular incremento de mujeres cabeza de familia que desean ingresar en las FAS, decir que en la primera promoción existían nueve casadas, cinco separadas y una divorciada, pudiendo decir que la gran mayoría de las que han ingresado hasta el momento eran solteras.

Una vez realizada la selección, comenzaban a plantearse de manera inmediata los problemas de infraestructura, logística y pedagógicos en la Academia, que hasta entonces se había dedicado en exclusiva a formar hombres. La indefinición inicial se manifestaba en opiniones, a veces encontradas, respecto a la forma en que debería realizarse ese período académico, al manifestarse algunos en favor de un recinto distinto del de los hombres - alegaban falta de espacio y dificultades de alojamiento (como siempre, el problema era el de los bidés)_, si bien la tesis final optó por una solución en la que el sistema de enseñanza y las instalaciones serían las mismas para hombres y mujeres. Seguramente muy poca gente había estudiado experiencias similares en otros países, en concreto las más conocidas de EE.UU., donde la controversia había tenido lugar muchos años antes. Así, en 1979, el que luego llegaría a ser secretario de la Armada americana, 
J. Webb, en un artículo en el que se mostraba contrario a que la mujer participase en unidades de primera fila, opinaba que la calidad de la formación en la Academia de Annapolis había descendido desde que las mujeres habían accedido a dicho centro - la ley de integración de las mujeres en las academias militares era de 1975-, posición que a buen seguro influyó para que, en 1982 y tras una serie de pruebas, se abandonase la práctica de los pelotones mixtos de instrucción básica en la Academia de West Point - la mujer accedió a la misma en 1976-, al estimar sus directivos que la presencia femenina destruía la camaradería entre alumnos, debido a lo que se definió como «elemento intangible difícil de evaluar», que impedía la superación de los jóvenes en ese entorno. Tal y como relata Foote, la oleada de protestas femeninas - con acusaciones de «prejuicios $y$ discriminación» por parte de las mujeres- hizo que no se consolidase una situación que consideraban de «segunda clase». En el caso británico, la instrucción académica en Sandhurst se realizaba de manera diferenciada para hombres y mujeres.

Aparte de alguna que otra anécdota de las primeras alumnas de la Academia de Ubeda, lo cierto es que no se produjeron disfunciones notables en el funcionamiento del centro y la integración de las mujeres puede considerarse satisfactoria; en ese sentido, y en línea con la investigación realizada por Hoiberg en centros navales americanos - descubrió que las mujeres estaban más satisfechas que los hombres y tenían una media de eficacia mayor-, A. Parrilla aporta datos en los que se comprueba cómo la alumna guardia civil está en todos los casos por encima de la media de cada curso, lo que demuestra la adaptación de las mujeres a un régimen académico que se entendía exclusivo de los hombres. Tan es así que, en esa primera experiencia, solamente solicitaron la baja voluntaria dos alumnas y ninguna de las mujeres tuvo que repetir curso, mientras que en la tercera promoción de los 63 repetidores cinco eran mujeres.

Sin embargo, no sería riguroso pensar que no han existido problemas de integración e incluso rechazo corporativo frente a un hecho de tanta trascendencia para la institución; así, aparte de la exigencia de determinados sectores de la sociedad para que la integración femenina en las FAS sea completa - que comprenda también el servicio militar obligatorio, en este caso como guardia civil auxiliar-, están todos los derivados con la necesidad de adaptar las infraestructuras existentes a las nuevas necesidades, para facilitar una pacífica convivencia, los derivados de la maternidad, el diseño de una carrera profesional para la mujer y todo lo relacionado con derechos pasivos, indemnizaciones familiares, etc. En cuanto a los rechazos internos, Shields considera que las FAS no son una organización que reciba o acomode bien a la mujer, al hundir sus raíces en «tradiciones masculinas sancionadas por el tiempo», lo que hace que los hombres, al sentirse amenazados en su situación, se muestren hostiles y no cesen de poner obstáculos a esa futura integración, llegando incluso a promover 
campañas de difamación en base a «prejuicios morales y de carácter», siendo ese rechazo mucho mayor en los de más edad y en los escalones básicos más que en los altos niveles del mando, aun cuando sea de más trascendencia la postura de estos últimos a la hora de intentar la integración.

No obstante, la mayor parte de autores consideran que la causa más habitual de conflicto sigue siendo todo lo relacionado con el sexo, cuestión que para Shields se convierte, por sus efectos devastadores, en uno de los obstáculos más graves para la integración, al hacerse «invasor, continuo y desmoralizador», y cuya consecuencia más dramática es que «degrada la lealtad institucional y socava los valores» específicamente militares. J. Davis, al analizar las actitudes y tratamientos de los hombres militares hacia sus colegas femeninas y las repercusiones en la vida profesional de éstas, llegó a la grave conclusión de que existe «una conducta moralmente repugnante» en el comportamiento de los hombres de la Marina estadounidense estacionados en el Pacífico, lo que provoca que el ánimo de las mujeres allí destacadas sea muy bajo. Afirma que éstas son consideradas como un «objeto de juego libre», por lo que la oficialidad - no sólo la masculinaacostumbra a solicitar sus favores, y que los centros de diversión tienen una "orientación absolutamente sexual», con lo que ello implica para unas personas que permanecen la mayor parte del tiempo dentro de las bases. Las mujeres aseguran que el desprecio de sus compañeros por las prostitutas asiáticas se extiende a ellas mismas y que el relevo del capitán del buque Safeguard -ofreció la venta por radio de 18 mujeres de su tripulación a unos coreanos durante la travesía - no es más que uno de los muchos casos que a diario se producen en las FAS americanas.

Recientemente, la presentación de denuncias por agresiones sexuales de 26 mujeres de la Marina de ese país contra 14 oficiales, durante una convención militar en Las Vegas, provocó airadas reacciones sobre lo que se consideraba falta de respeto hacia una institución honorable y, a consecuencia de ello, la dimisión del propio secretario del departamento. A pesar de todo, el futuro no se adivina tan negro como parece, ya que la situación en las bases del interior es algo más favorable y, respecto a las relaciones intersexuales, Prugh considera que no tiene por qué ser distinto a lo que ocurre en otras profesiones, dependiendo básicamente de la formación personal de sus miembros; en cualquier caso, y aunque existen graves problemas de adaptación, Shields asegura que las mujeres se integran con facilidad en los esquemas de la organización militar.

En el caso de la Guardia Civil, como era lógico, se impartieron severas instrucciones para que la convivencia en la Academia no se viese perturbada por este tipo de comportamientos, lo que no impidió que en la primera de las promociones se hubiesen fraguado más de 30 noviazgos entre alumnos de la misma, abriendo una nueva perspectiva - ciertamente originalen la historia de una institución donde la endogamia se consideraba algo consustancial al Cuerpo, de tal manera que, a finales de julio del 92 y 
recién salida la cuarta promoción con miembros femeninos, el porcentaje de casadas se ve incrementado de continuo, de las que una gran parte lo hacen con miembros de la propia Guardia Civil, tal y como se recoge a continuación:

\begin{tabular}{|c|c|c|c|c|}
\hline & Casadas & $\%$ & Con compañeros & $\%$ \\
\hline Promoción 94 & 59 & 29,9 & 46 & 77,9 \\
\hline 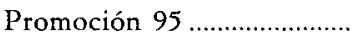 & 46 & 25,5 & 29 & 63,0 \\
\hline 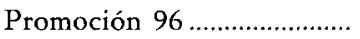 & 43 & 15,3 & 32 & 74,4 \\
\hline Promoción 97 .......................... & 17 & 5,8 & 13 & 76,4 \\
\hline TOTAL & 165 & 17,4 & 120 & 72,7 \\
\hline
\end{tabular}

A mayor abundamiento, puede ser ilustrativo el dato de que mientras en abril de 1992 el porcentaje de casadas con miembros del Cuerpo era del 71,2 por 100 , cuatro meses después es del 72,7 por 100 -lo que indica un incremento de porcentajes a medida que pasa el tiempo-, muchas de ellas con un compañero de promoción, poniendo de manifiesto una tendencia que es fácil de comprobar en la realidad, cual es el elevado número de parejas de novios que se forman desde la Academia y en los sucesivos destinos, lo que en el futuro puede elevar todavía más los índices expuestos anteriormente. ¿Se imaginan cómo puede inclinarse aún más la preponderancia institucional, en el momento que los hijos de estos matrimonios decidan continuar la profesión de sus padres? Se estará entonces ante una doble legitimación del tradicional concepto de bijo del Cuerpo que vendrá a complicar en mayor medida el análisis de fenómenos tan característicos como la endogamia y el autorreclutamiento.

Convendría entrar a continuación en el estudio de la problemática relativa a destinos de las nuevas guardias civiles, cuestión ésta de la utilización adecuada de la mujer en los ejércitos que Shields considera crucial, ya que la participación femenina ha seguido estrictamente limitada a campos y actividades tradicionales, en los que no suponía una amenaza para los derechos adquiridos por el hombre. Aun cuando hoy tiende a cambiar el panorama, la mujer no suele sentirse muy atraída hacia los destinos no tradicionales, pues, aparte de que suelen estar en término medio menos preparadas que los hombres, se encuentran ante un dilema de difícil solución, ya que si triunfan queda «cuestionada su feminidad» y, si fracasa, su afirmación femenina se hace a costa de su trabajo, toda vez que resulta casi imposible compatibilizar unos horarios irregulares con el insustituible papel de ama de casa, razón por la que una gran mayoría prefiere puestos con un horario fijo que le permita atender ambas responsabilidades. Mientras Fletcher asegura que las pruebas psicológicas demuestran que la mujer está mejor dotada para todo lo referente a «lenguaje, comunicación y trabajos 
escritos» - para P. J. Thomas es más responsable a la autoridad y menos propensa a romper reglas que el hombre-, Foote, aun cuando reconoce las diferencias biológicas de los sexos, estima que el único criterio para evaluar a la gente es «si son o no capaces de hacer su trabajo».

En el caso de la Guardia Civil, y seguramente con objeto de acallar las críticas que hablaban de posibles favoritismos para las mujeres, se optó por el criterio de igualdad absoluta a la hora de elegir sus primeros destinos, rigiéndose por el estricto orden de las calificaciones obtenidas en el curso, de tal manera que la distribución de destinos es la que figura en el cuadro 3. Se ha procedido a la separación de la tercera promoción de las dos primeras, ya que mientras los de aquélla todavía ocupan destinos forzosos, los de éstas ya han tenido ocasión de cambiar su primer destino. Es por ello que se observa una clara disminución de efectivos en los servicios peculiares (Rural) y menor en los relacionados con aduanas y fronteras (Fiscal), manteniéndose los núcleos de servicios fijos de seguridad (edificios e instalaciones) y un claro incremento en los servicios de información y burocráticos, en este último caso siempre con el recelo permanente de los hombres, que ven peligrar sus posibilidades de ocupar dichos destinos. Más insignificantes son las cifras de las especialidades, ya que es necesaria la realización de un curso previo para acceso a las mismas. Hay que resaltar que, en aplicación de esas políticas de igualdad, las mujeres policías se ven obligadas a enfrentarse con situaciones tan conflictivas como pueden ser la lucha antiterrorista, unidades antidisturbios o patrullaje en zonas de alta criminalidad.

No es una cuestión que afecte de manera directa a una institución militar cuyas funciones son en su mayoría policiales - se trataría de una función más disuasoria que de combate, en la línea de misiones que desarrollan muchos ejércitos en la actualidad-, pero no está de más hacer algún tipo de referencia al tema de los destinos para mujeres en unidades

\section{CUADRO 3}

Destinos de tres primeras promociones

\begin{tabular}{|c|c|c|c|c|}
\hline & I y II promociones & $(\%)$ & III promoción & $(\%)$ \\
\hline Rural & 95 & 27,02 & 222 & 36,39 \\
\hline 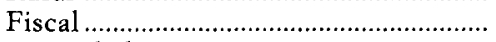 & 28 & 7,56 & 60 & 9,83 \\
\hline 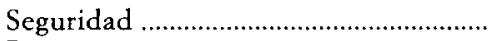 & 123 & 33,24 & 207 & 33,93 \\
\hline 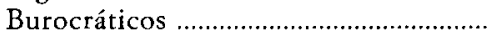 & 56 & 15,13 & 60 & 9,83 \\
\hline 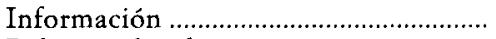 & 41 & 11,08 & 44 & 7,21 \\
\hline Policía judicial & 11 & 2,70 & 11 & 1,80 \\
\hline Tráfico & 3 & 0,80 & 3 & 0,49 \\
\hline Servicio marítimo & 3 & 0,80 & 3 & 0,49 \\
\hline
\end{tabular}

FUENTE: Elaboración propia sobre datos DGGC. 
de primera línea o de combate, ya que a E. Foote, como a otros expertos, le resulta muy difícil diferenciar lo que es frente de lo que es retaguardia -en la invasión de Granada, un jefe de policía militar hubo de rectificar su orden de no desembarcar mujeres, debido a las airadas protestas de las mismas-, indefinición que a muchos jefes les plantea serias dudas sobre el número de efectivos con los que puede contar en un caso extremo. Esta prohibición significa un obstáculo a la defensa nacional e influye negativamente en la carrera profesional de las mujeres, al limitar su acceso a determinados empleos; además, dado que se ha producido una integración en todos los aspectos, el no haberlo hecho aún en éste les impide lograr una orientación institucional completa de su trabajo - tras finalizar la guerra del Pacífico se pudo comprobar que el reducido número de mujeres que habían participado en la misma desarrollaban una intensa adhesión a la institución-, pues, como afirma Ramsey, sólo habrá una verdadera integración cuando la mujer ocupe esos puestos de combate reservados tradicionalmente a los hombres, medida de la que, por cierto, no es partidaria.

El planteamiento de que la entrada en combate de la mujer legitima su petición de un status cívico y político igual al de los hombres es criticado por Feld, desde una perspectiva histórico-sociológica; sin embargo, los descensos en las tasas de natalidad - lo que Thomas denomina «erosión gradual» del concepto combate - son una amenaza real para poder completar esas unidades sólo con hombres, y, por otra parte, en los conflictos bélicos modernos es cada vez más similar el riesgo en dichas unidades y en las que se dedican a apoyarlas y administrarlas, lo que hace presumir una mayor participación de la mujer en las mismas.

Sin duda, la acusación que con más frecuencia se dirige a las mujeres que pretenden iniciar la carrera militar es la de su escasa permanencia en el puesto de trabajo, bien sea porque se tiene que dar de baja temporal por sus condicionamientos fisiológicos o porque su desconocimiento de lo que les espera en esos ambientes les obliga a solicitar el abandono definitivo de dichas organizaciones; en cualquier caso, esa pretendida debilidad femenina aconseja hacer algún tipo de precisiones al respecto. Es cierto, como estudió Landrum, que la mujer sufre problemas de permanencia y desgaste en su actividad castrense, relacionados con causas como las «funciones en combate, actitud de los varones, vida familiar en el Ejército y familias con un solo progenitor», lo que ha provocado quee en las FAS de los EE.UU. se alcancen porcentajes de abandonos femeninos del 45 por 100 tras los primeros períodos del servicio - alrededor del doble de los hombres-, lo que para Levin se debe, entre otras razones, a presiones ambientales y una aceptación demasiado lenta de dichas incorporaciones, aunque oficialmente no se reconozca así, pues si al principio se considera como «algo exótico», luego puede pasar a convertirse en «objeto sexual» y muchas en un auténtico «desprecio» por parte de sus colegas masculinos. 
En lo que sí hay acuerdo unánime es en considerar los problemas de embarazo y cuidado de los niños como la causa principal de las bajas femeninas - si para Fernández Vargas la maternidad es «la gran cuestión subyacente» en todo este debate, Ramsey considera que «la maternidad no es compatible con el servicio»-, ya que, como señala el propio Levin, aunque se trata de funciones que teóricamente debieran ser compartidas por el hombre, lo cierto es que tiene «implicaciones especiales» para la mujer, al ser la que se encarga de forma más habitual de las funciones domésticas y del cuidado de los hijos -el hombre suele continuar en su trabajo para mantener a la familia-, por lo que, a la hora de elegir, la mujer opta por la familia frente a la profesión. En el mismo sentido, Shields considera esta cuestión como una de las más controvertidas para la integración femenina, debido a sus «implicaciones de disponibilidad» —en la Guardia Civil es muy frecuente que los hombres planteen una situación de su Unidad en la que predominen las mujeres y se queden embarazadas de manera simultáneay a las alteraciones que puede producir en la «cohesión de la Unidad y la eficacia del equipo», lo que, como queda expuesto, puede provocar «resentimiento masculino» por sobrecarga de trabajo, que permite a dicha autora concluir con que la elección de tener un hijo «no altera de la misma manera a su capacidad de trabajo», razonamiento ciertamente machista y que trata de rebatir el senador americano Proxmire, pues si de lo que se trata es de pérdida de tiempo, mucho más pierden los hombres con el «alcohol y las drogas». Otras razones que apunta Shields se refieren a la existencia de un «entorno físico desagradable», que provocan insatisfacción en el trabajo, o descontento con respecto a los salarios, por cierto no demasiado habituales en la mujer militar.

Ante todo este cúmulo de dificultades, no debe extrañar que las mujeres figuren en las calificaciones más bajas de satisfacción profesional y, debido a ello, sean más propensas a abandonar las FAS, tendencia que, sin embargo, se altera en cuanto superan el primer período de servicio, siendo entonces los hombres los que abandonan con más frecuencia. En contra de esa opinión mayoritaria, recientes estudios de la CEE demuestran que la mujer no supera al hombre en tasa de inactividad, en tanto Webster y Booth, tras examinar niveles e índices de rentabilidad y calidad en personal sanitario de las Fuerzas Navales de los EE.UU., concluyeron que las mujeres son tan competentes como los hombres, si como medida de la competitividad se toma la «culminación del servicio y la permanencia en activo por un año».

En el caso de la Guardia Civil, todavía es muy prematuro tratar de contrastar esa causalidad, dado el escaso tiempo que llevan incorporadas al Cuerpo las mujeres, si bien se pueden citar algunos datos al respecto; así, hasta el pasado mes de abril, solamente siete habían solicitado la baja una vez incorporadas a sus destinos - lo que permite constatar un nivel de integración muy aceptable, debido quizá a que ya les era conocido el 
contexto profesional a la mayoría-, siendo 31 las que causaron baja académica en los cuatro cursos que van impartidos, cifra que se puede considerar significativa del rechazo que, en un primer momento, produce el enfrentarse con un régimen de vida totalmente distinto al que habían llevado con anterioridad. En cuanto a la influencia de los embarazos en la actividad profesional de la mujer, aún no es posible llevar a cabo un análisis en torno a esa cuestión - la mayoría siguen siendo solteras o recién casadas-, si bien tuvo una amplia trascendencia en los medios de comunicación el caso de una guardia embarazada que fue arrestada dos veces por presuntas irregularidades en la utilización de la baja médica -uno de ellos por no disponer de uniforme adecuado para asistir a los actos de la patrona-, sanciones posteriormente anuladas en la instancia judicial; en este caso llama la atención el hecho de que no se hubiese utilizado el mecanismo legal contemplado en el artículo 74.5 de la Ley de personal militar profesional (1989), tal y como recordaba un escrito de unos meses antes de la propia Dirección General, y según el cual se podrían establecer «peculiaridades» para la mujer, derivadas de sus «condiciones fisiológicas específicas», por las que se les asignaría un «puesto orgánico distinto del que estuviese desempeñando», así como la necesidad de disponer en los depósitos de vestuarios de las prendas adecuadas para estos casos. De lo que no cabe ninguna duda es de que la publicidad dada al caso sirvió para que muchos se diesen cuenta por vez primera de algunos problemas consustanciales a la presencia femenina en una institución como la Guardia Civil.

El abrir la vía del ingreso a la mujer no suponía solamente su participación en las tareas básicas del guardia, sino que, en virtud de la existencia de una escala única en el Cuerpo, podría optar al ingreso en los empleos superiores a medida que fuesen cumpliendo las condiciones exigidas; de esa manera, las pertenecientes a la promoción 94 han podido tomar parte en la última convocatoria de ascenso a cabo, con los resultados siguientes:

Se inscribieron 94 -prácticamente la mitad de las que ingresaron, lo que refuerza esa tendencia institucional ya señalada-, de las que 67 quedaron excluidas de la prueba cultural por acreditar titulación de bachiller superior, buena muestra del alto nivel de estudios también apuntado, causando baja 11 de ellas por diversos motivos antes de examinarse. A esas 56 se les sumaron 13 aprobadas sin titulación, lo que daba una cifra de 69 aspirantes a la segunda fase (pruebas de conocimientos profesionales, físicas y médicas), resultando aprobadas al final 38 mujeres, 34 con titulación y 4 sin ella, las cuales realizarán el curso que les otorgará la aptitud para el ascenso a cabo, dando así comienzo a una carrera que, en teoría y según la reglamentación vigente, podría llevarlas a lo más alto del escalafón. Mientras tanto, a la Academia Especial de Oficiales todavía no ha llegado ninguna mujer - de forma un tanto paradójica, en dicho centro permaneció durante el último curso escolar una oficial de policía de Andorra, perteneciente a un cuerpo de naturaleza totalmente civil-, lo que permite, 
a través de la entrada gradual por las escalas básicas, ir adquiriendo una cierta experiencia en las labores de mando por parte del personal femenino, al tiempo que se hace más intensa la inicial orientación institucional de ese contingente. El general Calderón entiende que si bien para el mando «de gestión» la mujer sólo necesita la formación técnica específica, para el «operativo» es conveniente dejar pasar un tiempo de rodaje y aclimatación.

Después de todo lo expuesto, y en un a modo de epílogo - por fuerza provisional en el caso de la Guardia Civil-, podría establecerse, siguiendo a Shields, que la mujer que ingresa en un cuerpo militar se siente más atraída hacia la institución que los hombres, ya que no suele plantearse esa opción solamente como un empleo, al considerar que se trata de instituciones especiales que ofrecen «beneficios excepcionales como la disciplina y la aventura»; los estudios realizados hasta el momento permiten afirmar que no ven al Ejército como un patrono y su presencia se mantiene en base a valores más compatibles con el modelo institucional, frente a las conductas y actitudes masculinas mucho más próximas a los presupuestos ocupacionales, empleo fijo y salario, lo que no quiere decir que no sean también tenidos en cuenta por la mujer. Ese predominio de lo institucional sobre lo ocupacional no es óbice para que en la práctica surjan numerosas dificultades para conseguir la necesaria adhesión e identidad a la institución, toda vez que, como ya quedó expuesto, «la milicia no integra realmente a la mujer», en concreto debido a las obligaciones familiares y, dentro de ellas, a las derivadas de la maternidad. Una vez nacido el hijo, las madres militares tienden a asumir valores ocupacionales -predominan los intereses laborales y familiares sobre los de la profesión- y, con ello, se interrumpe el proceso de asimilación iniciado al ingresar en el Ejército; los horarios regulares y destinos más cómodos son entonces los deseados por ellas, de donde se deduce que la mujer que piensa hacer carrera en las FAS no desea generalmente ser nunca madre.

Toda esta problemática llevó al ejército de EE.UU. a incorporar servicios familiares gratuitos que permitiesen crear un mayor apego institucional de las madres militares, para lo cual se ubicaron en las bases guarderías infantiles que permitiesen compaginar ambas obligaciones, dejando para los fines de semana el resto de faenas domésticas. La experiencia demostró que son las madres solteras las que mejor compaginan esas actividades $\mathrm{y}$, al mismo tiempo, se produjo una mayor vinculación hacia una institución que era capaz de preocuparse también de su familia. Por eso, Shields considera que, en el dilema institución-ocupación, la mujer se ha manifestado históricamente mucho más institucional que el hombre, al sustentar su profesión en valores vocacionales y de «sacrificio personal», consustanciales a su carácter y condición de madre.

Dado que es evidente la tendencia a incrementar el número de mujeres militares -bajón demográfico y altas tasas de paro en Occidente han hecho que, en los últimos veinte años, se haya multiplicado su número por 
cinco en la OTAN-, para Vaught, las nuevas reclutas, que buscan sobre todo «variedad y movilidad», sólo necesitarán algunas «disposiciones especiales por maternidad» para conseguir su integración en las FAS. Esa facilidad femenina para asimilar la jerarquía y la disciplina le sirve a Prugh para calificar el futuro de «prometedor», no sólo ya por la necesidad de ejercitar el principio de igualdad de oportunidades, sino por la «creciente tecnificación de los servicios», lo que hará indiferente el sexo del militar que tenga que prestarlo; si bien reconoce que «la tradición y algunas particularidades biológicas» pueden incidir negativamente en el proceso de integración, no debe impedir el avance en otros quehaceres más tradicionales y en los de mayor riesgo y responsabilidad.

Levin entiende que, aun cuando los salarios sean iguales, la mujer resulta menos cara que el hombre, pues la mayoría de estudios demuestran que «son más inteligentes y consiguen mayores puntuaciones» -al aprender con mayor rapidez, el coste es menor-, con lo que es más fácil dirigirlas; además, suelen ser algo mayores que los hombres al ingresar -en la Guardia Civil, la edad media de la mujer es de 21,42 años, frente a 20,11 en los hombres de la 94 promoción-, «más educadas, obedientes y bumildes» frete a sus mandos, delinquen menos y se casan con más frecuencia, lo que le permite concluir con que se trata de «una buena inversión». Por su parte, Foote se queja de la atención que los estudiosos prestan al papel de la mujer militar, ya que, a diferencia de los hombres, son «constantemente revaluadas», además de que las restricciones que se le ponen en el momento del acceso empeoran una «situación económica y social ya desigual».

Aun cuando este trabajo ha querido, de forma intencionada, centrar su análisis en el caso concreto de la mujer guardia civil —una síntesis de militar y policía-, no resulta ocioso hacer una referencia somera a la situación de las mujeres en el resto de cuerpos policiales españoles; así, mientras las nuevas policías autónomas cuentan con contingente femenino desde sus inicios (entre el 8 y el 10 por 100) -en el caso vasco no fueron admitidas en la I Promoción-, el Cuerpo Nacional de Policía dispone de 780 mujeres, distribuidas por escalas como sigue: en la Básica, 649 — siete de ellas como oficiales (similar a la cabo de la Guardia Civil)_; en la Ejecutiva, 131; dos como inspectoras jefe; no contando con ninguna en las escalas de Subinspección y Superior, por obvias razones de antigüedad en el Cuerpo.

Tras todo lo expuesto anteriormente es posible concluir afirmando que la mujer en la Guardia Civil presenta unos rasgos que permiten considerarla dentro del esquema institucional, tendencia que se verá reforzada en el futuro con el acceso a niveles superiores de jerarquía, lo que no obsta para que se tengan que llevar a cabo los estudios necesarios para analizar las experiencias adquiridas y así poder ir desarrollando una normativa que sirva para hacer frente a una problemática totalmente nueva para el Cuerpo, con lo que no sólo se conseguirá una mejor integración, sino que redundará en una mayor eficiencia para el servicio que tengan encomendado. 


\section{BIBLIOGRAFIA}

Davis, J. (vicepresidenta ejecutiva del Instituto de Análisis de Política Exterior de Cambridge - Massachusetts - y presidenta de la Conferencia Especial del Departamento de Defensa de los EE.UU.): Reproducido del NYT por El Pais, 18-X-1987.

HoIBerG, A.: «Women in the navy: morale and attrition», y LANDrum, C.: «Women in the allvolunteer force», en Armed Forces and Society, 1978.

KANTER, R.: Man and Woman of the Corporation, Basic Book, 1977.

La mujer en las Fuerzas Armadas en España, Ed. Ministerio de Defensa, 1991.

- Alemany i Roca, J., directora de la Comisión Interdepartamental de Promoción de la Mujer, «La incorporación de las mujeres en el Ejército».

- Calderón, J., general director de la AGM, «La mujer en puestos de mando y combate».

- FERnÁNDEZ VARGAS, V., Investigadora del CSIC, «Mujer y Fuerzas Armadas».

- Ramsey, G. K., Coronela del WRAC, «Problemática suscitada por la presencia de la mujer en puestos de mando y combate en Gran Bretaña».

- Thomas, P. J., psicóloga del NPRDC, «Integración de la mujer en la Armada de los EE.UU. de América».

LEvin, T. (profesora de la Universidad de Maryland -EE.UU._- y especialista en cuestiones relacionadas con la mujer): Las mujeres y el ejército, informe reproducido en El País, 26-VII-1985, en el que se cita a E. Foote, coronel jefa del Grupo 42 de Policía Militar.

Parrilla, A.: La mujer en la Guardia Civil: Diferencias significativas, 1991 (inédito).

PRUGH, P. (capitán auditora del Ejército de los EE.UU.): Opiniones recogidas en $Y a, 16-\mathrm{V}$ 84.

SHIELDS, P. M.: «El rol de los sexos en las Fuerzas Armadas», en Lo militar más que una profesión, Ch. C. Moskos y F. R. Wood, Ed. Ministerio de Defensa, 1991.

VAught, W. L. (general de Brigada -EE.UU.-), y FletCher, K. (oficial de la Royal Navy - GB-), ambas asistentes a la XIII Conferencia del Comité de Personal Femenino FAS (OTAN), 1987.

Webster, E. G., y Booth, R. F.: Success and Failure Among Male and Female Navy Paramedical Specialists, Journal of Community Psichology, 1976.

WeEB, J.: Datos de su artículo recogidos en NYT, 8-IV-87.

Revistas Guardia Civil y Española de Defensa.

Boletines Oficiales del Estado, de Defensa y Guardia Civil. 